\title{
Reflections of a Social Constructivist on Teaching Methods
}

\author{
Dr. Erdem Erciyes \\ The Turkish Gendarmerie General Command, Turkey
}

Doi:10.19044/ejes.v7no4a2 URL:http://dx.doi.org/10.19044/ejes.v7no4a2

\begin{abstract}
This paper aims to examine how the combination of theory and practice work effectively in teaching and supporting the learning process. Action research methodology was followed in the research by designing a plan of action in the practicing environment. The research focuses on the interaction of the researcher and participants. Mixed approaches of social science heavily influenced this research by implementing social constructivist understanding of teaching methods. The mixed teaching approach of Biggs and Tang, constructive alignment, was used in teaching sessions by utilizing social constructivist theory, reflexivity, intended learning outcomes, assessment tasks, peer review, and teaching learning activities. The findings of this research present practical recommendations for scholars. Constructive alignment feedback should encourage students to express whether or not their learning is improved in relation to learning outcome. Preparing more visual aids and a greater relaxed atmosphere would possibly help to gain an enhanced level of students' attention for an indirect but more efficient participation. There is an urgent need for teaching skills through master-classes workshops such as "Teaching with Emotional Intelligence", "Assessment of/for Learning", and "Creating Productive Classroom Environments".
\end{abstract}

Keywords: Social constructivism, constructive alignment, self-reflexion, teaching methods, academic teaching.

\section{Introduction}

Social constructivism seeks to understand how humans interpret or construct issues in social, linguistic, and historical contexts (Schwandt, 2001). The knowledge of social constructivism is shaped by oneself and the participants' experiences, views, and background knowledge (Creswell, 2013; Smith et al., 2012; Howell \& Annansingh, 2013). "Constructions are not more or less true in any absolute sense but simply more or less informed or more 
sophisticated. Constructions are alterable, as are their associated realities" (Guba \& Lincoln, 1994, p.111).

Social constructivism itself is created through interaction of teacher and students. As a result, constructivism creates and develops knowledge through the investigation process. The results are then created by consensus and individual constructions with the investigator's compositions (Howell \& Annansingh, 2013). In this research, the researcher followed a social constructivist view of learning which emphasizes the importance of shaping knowledge by increasing the participation of learners (Scribner, 1985; Cole, 1990; Rust et al., 2005).

During the researcher's undergraduate period and after his graduate studies, he was not concerned of the possibility of becoming a professor in the future. However, in lieu of focusing on teaching methods, he only concentrated on passing his university courses. Yet, at the stage of his doctorate degree, his outlook changed as this degree gave him the option of becoming a professor in two years. Therefore, in line with this view, he has been trying to develop his teaching skills through analysing the literature of teaching approaches and observing the methodology of professors. To complement these means, he has also been relying on a few teaching experiences that he previously had. Back in 2004, for a period of 4 months, the researcher taught a class on military writing rules. Later in 2012, he taught a class on military management systems for a three-month course. Although these short teaching periods may not be deemed as enough experience for an instructor, yet they did provide a basic understanding of the methodology of teaching classes. Furthermore, he has experience working at army human resource management units during his professional working years in the military and as a result he is rather familiar with practices of army management and its writing rules. Also, has tried to transfer this practice-based knowledge to other students. Presently, the researcher tasked himself with discovering more efficient ways to link students with each other, and instructions, with the goal of passing on his know-how from research and experience to them.

The course in question is one regarding the topic of leadership where the students had learned the main motivation theories in existing literature. This was done a week before commencement. For this reason, the assumption of their basic familiarity and understanding regarding motivation concepts could be taken just the way it was given. Moreover, some of these students have had work experience as foreign employees in Switzerland. To this end, their participation and opinions were very valuable in the lesson. 


\section{The Research Methodology}

The research design of the study illustrates interactions of the researcher and inquiry in social science which investigates ideas and activities that are difficult to observe or interpret. This research establishes flexible, interactive, explorative, and qualitative research designs. In addition, it provides an in-depth understanding as it relates to the research topic. Although utilizing abductive reasoning is of significant importance, it helps to establish a more flexible and free research environment during the process of knowledge production. Based on the methodology of the research, action research was used. The researcher was involved actively at every step of the research process and reflected his observations from praxis.

Lewin et al. (1939), as the pioneers of action research, combined their work with the idea of doing experiments. They utilized the results of experiments gained in the workplace and took them well beyond their sociotechnical design to develop a theory (Gustavsen, 2001, 2008; Bradbury et al., 2013). Thus, action research deals with cases in the field or real world (Greenwood \& Levin, 2000). Nowadays, action research is mostly used for enhancing conditions and practice in administrative, leadership, social, and community setting environments (Craig, 2009). The inquiry of action research identified the research problem and designed a plan of action in the practicing environment. To reach a conclusion for improving practice, the observations and reflections of the researcher were gathered and analyzed. The research methodology provided involvement of the researcher.

The plan of the research comprises of five steps: (1) Session design, (2) Teaching session, (3) Learning outcomes (4) Peer review, (5) Selfreflection. Data gathering for this action research was in the second and third steps. Before action research, formal permission was taken from the university. In addition, details of the research were shared with the participants and their consents were granted.

Structure, learner activity and participation, professionalism materials and resources, areas of strengths and weakness, and overall impression are main headings of data analysis. These headings were also provided to the research colleague before the peer review section.

The researcher gave two hours teaching lessons as a guest lecture on a second-year undergraduate leadership course in a private Swiss university. Ten students of different nationalities - Russian, Azerbaijani, Swiss, Swedish, Indian, Romanian, Ukrainian, and Pakistani - participated, while only one was of the female gender. Also, some of the students have business experience in the multinational work environment. While choosing university and participants, random samplings and volunteerism principle were utilized.

During the teaching session, the researcher spoke about "Motivation concept", as he was very familiar with it because he has been working on it 
for almost two years. The researcher wanted to show students how theory and practice can complement each other and how knowledge gained from their academic life can be useful in their subsequent work cycle. Then again, he did not view this lesson as a one-way street. The students' participation was also an important element of the project because an essential aspect of his studies is the examination of the role of foreign employees in a multinational work environment. While looking at the students' profiles - such as their work experiences in a multinational setting, diverse nationalities, living in a cosmopolitan environment, and education in international universities with professors from a wide array of countries - he thought that it could be a good opportunity to gain from their perspectives for the advancement of his doctoral thesis as well.

The researcher asked many questions from the students, initiated numerous discussions, and encouraged them to express their opinions freely while in his class. Thus, this helps to stimulate their participation in support of the teaching sessions. The belief behind this method lies on the importance of creating an ongoing relationship between the two main actors in a learning process: the teacher and the student. Moreover, he had two general aims for this process: firstly, transferring his knowledge, and secondly, gathering the students' perspectives to reflect them back onto his understanding. In order to realize these aims, and to minimize the separation gap which normally exists between teachers and pupils, he tried to follow a friendlier approach rather than the customary approach. The main difficulty he foresaw was the session's starting time, 9.30 AM. Since it is the first class of the day, it became important to find a mechanism for gaining the students' attention. As a result, he would begin class by recounting some jokes. Afterwards, he would talk about future projects, discuss general daily issues, and share some anecdotes. At the end of all these conversations, he would usually connect them with the doctoral topic and tried to infer to the students what Kant (1995) had mentioned when he concluded that "theory and practice are two sides of the same coin, and therefore, they should not be separated but should instead be reflected whole in each other".

\section{Findings}

Under a constructivist approach, the researcher specially focused on the interactive discussion element by looking at the student's own perspective about motivation. He also stated how they constructed the meanings of motivation. Basically, he looked for the meaning of motivation to them. After then, he opened a discussion about the definition of motivation and later developed one general definition that was shaped by the students' own perspectives. Finally, he connected this definition to similar previous motivation theories. Interestingly, the students brought their individual experiences and tried to create a common definition by listening to each other 
views and comparing them with prevalent theories. Hence, this constructive approach helped him so much to combine theory and practice.

Furthermore, his approach does not only take into consideration constructivist theory but a combination of theories, intended learning outcomes, teaching/learning activities, and their evaluation. He followed Biggs and Tang's (2011) constructive alignment teaching approach. Rather than following traditional theory-based approaches, he aims to focus on what students should do to learn effectively. According to this approach, two principles are necessary: "a constructivist theory of learning and alignment between the intended learning outcomes of the course, the teaching/learning activities and the assessment tasks" (Ibid: 95). "Intended learning outcomes are written from the students' perspective, indicating the level of understanding and performance they are expected to achieve as a result of engaging in the teaching and learning experience" (Ibid: 100). In the feedback process of teaching sessions, he included the intended learning outcomes in each teaching session as activities and assessed if the students have reached the intended outcomes or not.

In regards to his feedback, he asked the students at the end of the session if they gained a better understanding about motivation concept, if they can explain how motivation theories have been shaped by history, and if they can explain how to combine theory and practice in the research process. Moreover, in the beginning of the session, he presented intended outcomes to the students. At the end of the session, he returned to the page of learning outcomes and inquired from the students if they felt the learning outcomes have been achieved, and they confirmed that such was the case. However, one of the shortcomings was that he should have asked them how they learnt what he taught them. He realized that within constructive alignment, feedback should focus on what Biggs and Tang $(2011$, p.97) refer to as "not only what is to be learned, the topic, but how it is to be learned and to what standards". Thus, the teacher should encourage students to express if their learning is improved in relation to learning outcome.

\section{Discussion}

Reflexivity provides a mutual and continuing interaction between the self and knowledge. The self develops knowledge but it is also developed through knowledge (Alvesson \& Sköldberg, 2009). Teaching and learning have a similar relationship which can be defined as mutual reflective. Thanks to the interaction between teacher and learners, the one teaching may come to learn new things from the students as well. Therefore, this reflexive relationship establishes and changes the person teaching as well.

The researcher did not spend an inordinate amount of time to develop the presentation content because before preparing it, he spoke with the regular teacher of the class regarding what the students had already learned. Also, he 
examined the class syllabus and later realized that the research topic fit rather well with the flow of his lessons. With this understanding, he decided to devote two hours of teaching the students in this process after they had learned the main motivation theories. He developed the presentation information based on his doctoral thesis. In lieu of spending too much time gathering information, he focused on the session design and plan, and on how he could improve students' possible assimilation of knowledge. Moreover, he also saw this lesson as an opportunity. He desired to see theoretical knowledge reflect upon those who have basic information about motivation, culture and leadership, and also those who have some work experience in a multinational work environment. As a result, he constructed the lessons' instructions based on the students' participation and his doctoral research. However, he came to realize that, as an alternative to having asked many questions in order to stimulate their participation, he could have prepared more visual aids and a greater relaxed atmosphere to have possibly gained an enhanced level of their attention for an indirect but more efficient participation on their behalf.

Moreover, in the pursuit of creating a sincerer class environment, despite the strategy of sharing anecdotes in a humorous context, he was not as successful in gaining the students' full attention as had desired. Thus, this is mainly due to his formal academic approach. Looking back, he believes this was perhaps his principal mistake with roots lying on the fact that a sophomore undergraduate class normally lacks the proper philosophic background necessary for the success of the approach he utilized. Even yet, the students ended up learning general leadership, culture, and motivation theories. Likewise, he came to realize that the students had learned only mere common and basic materials from their previous lessons and surprisingly had forgotten many points which they had been familiarized with merely a week before. For his future lectures, one of the first things that he will take into consideration is simplifying his arguments per the level of students' discernment.

In the two hours' lesson he delivered as a guest lecturer, he did not relay his session plan and presentation to the regular teacher of the class in advance. Instead, he only examined the class syllabus and generally discussed what he had seen him talk about in his session. However, rethinking the situation according to his current conclusions, he realizes that if he had consulted with the regular teacher of the class prior to delivering his lesson, most likely she could have warned him about the level of the students' understanding so he could have avoided speaking over their heads and planned his session accordingly. Therefore, he can admit now that he had falsely assumed that for the planning of the lesson. Also, he should only take into consideration his own perspective of the manner in which the class should be conducted. Yet it is obvious that the regular teacher of the class was an integral component of the process. This, however, is just as instrumental as his own 
knowledge and the successful planning of the session. Hence, the proper strategy aims to combine his own knowledge of theory and practice with the understanding and experience of the regular teacher, vis-à-vis his students' background and frame of mind.

Feedback has been recognised by many scholars as the most important component of the learning process (Hattie, 1987; Black \& William, 1998; Gibbs \& Simpson, 2002; Rust et al., 2005). According to the social constructivist approach, students' active participation in response to the feedback process is just as important as an element (Rust et al., 2005). As a result, students have been encouraged to participate in feedback activity which is very important for reaching intended learning outcomes.

As a public-school graduate, the researcher has attended such institutions even for his higher education pursuits. Likewise, his previous teaching experiences were rendered in public school settings. According to his limited experience, student profiles are different depending on if they are attending public or private university. In the recent class, which he conducted, unfortunately a number of the students seemed as if they were not pursuing their higher education out of their own freewill and were perhaps forced by circumstances, such as their parents' desire to attend. Also, he made this conclusion based on his observations of their behaviour, such as a few who seemed aloof during the lesson. Still, he did make a special attempt to involve them in the discussion and learning process but they did not show any interest to answer any of the questions put to them. Even when he heard something incorrect but meaningful from them, he tried to encourage their independent opinions. Still, he felt as if there was something more that he could have done to reach them. For example, in the planning phase of his session, he could have prepared a more flexible and adaptable strategy that took into consideration this little but important detail.

In order to gain deeper and well-defined reflections, peer review activity was also utilized in this research. It has two dimensions. Firstly, the research was reviewed by his colleague. He viewed this peer review activity as an opportunity and tried not to err in his judgement. Listening to an external opinion is very useful for finding one's strengths and weaknesses. According to his reviewer, there are no problems regarding his level of knowledge, way of presentation, or demonstration of special issues in order to raise students' class participation. His main problem seems to lie in finding ways to simplify the information. The review also helped him to remember one of his communication problems. In his conversations, he falsely assumes that the person listening to him must have some basic knowledge of what he is speaking of. Conclusively, there is no need to discuss the relevant details to help them fully understand what he is trying to say. Consequently, he needs to learn the methodology for expressing himself in a more comprehensive and 
simplified manner, and not just as a lecturer. Another important lesson expounded by the review was the importance of actively utilizing short clips and videos in a lecture. For his next lecture, he will give special attention to this review.

For the second stage of the peer review project, he reviewed his colleague's weaknesses and strengths. However, even before beginning the review, he made a mental map of what constitutes positive and negative comportments of a teacher. This process was not just very useful for the purposes of the review but also because it helped him remember his previous teaching experiences. In addition, during the review process, he got the opportunity to compare his teaching approach to that of his colleague. Observing this different method helped him with the realization of important details regarding teaching, such as: how to provide clarity, how to establish good communication between teacher and students, and how to discern the level of students' understanding.

In his future lectures, he is planning to attain more knowledge from student feedback while he is constructing his lecture. In order to achieve this, he will ask for their anonymous written feedback. It would also be helpful to ask oneself: "If I was one of my own students in this class, what would raise my interest in the topic at question?" Therefore, he will put himself in the students' shoes next time he is to prepare a lecture. One of the good things that he admired about his colleague was how she developed her teaching technique according to the profile of the student. She connected the lesson with his special interests. It has to be taken into consideration though her lessons were administered to individuals on a one-to-one basis, which made it more conducive to focus on students' profiles. In addition, the same technique would be more difficult in regards to large classes. For larger classes, perhaps, it would be more realistic to focus on the overall profile of the class and the lessons would be tailored accordingly.

Another issue which the peer review opportunity made him aware of is that in order to discover the level of the class and students, it is perhaps a good idea to administer an introduction test to the students and form the class and teaching approach according to the results. Another important lesson which he learned from his colleague is to put the same question to the students from different angles and perspectives in order to reach them more efficiently. This approach reminded him of Einstein's famous quote: "Insanity is doing the same thing over and over again and expecting different results." Thus, he must learn to utilize different approaches with the goal of reaching the same destination. Overall though, it was very useful to discuss teaching techniques with a colleague. Sharing mutual ideas provided a better understanding of learning and developing efficient ways of teaching. 


\section{Conclusion}

The researcher has a very limited teaching experience and this limited experience becomes a valuable opportunity to highlight what is weakness in teaching. Most especially, during peer review process, he has benefited from his colleague's teaching approach because contrary to him, she is an active researcher and has many experiences about teaching. Therefore, her methods such as providing sincere teaching environment and using different teaching incentives gave him some clues about how to develop a good teaching exercise. He has also realized that he should observe more teaching sessions of experienced scholars and he should seek voluntary teaching opportunities for himself to gain more experiences.

In addition, the two-hours teaching session has helped the researcher to see areas that needs improvement, such as gaining the students' full attention as desired, simplifying arguments, and preparing a more flexible session plan. In order to develop teaching ability, he concluded that there is an urgent need for a more professional development in teaching. Examples includes teaching skills master-classes workshops such as "Teaching with Emotional Intelligence", "Assessment of/for Learning", and "Creating Productive Classroom Environments".

In a nutshell, constructive alignment feedback should encourage students to express if their learning is improved in relation to learning outcome or not. Preparing more visual aids and a greater relaxed atmosphere has possibly gained an enhanced level of students' attention for an indirect but more efficient participation. Therefore, there is an urgent need for teaching skills master-classes workshops such as "Teaching with Emotional Intelligence", "Assessment of/for Learning", and "Creating Productive Classroom Environments". 


\section{References:}

1. Alvesson, M. \& Skoldberg, K. (2009). Reflexive methodology, $2^{\text {nd }}$ ed. London: Sage Publications.

2. Biggs, J. \& Tang, C. (2011). Teaching for Quality Learning at University, $4^{\text {th }}$ edn., Berkshire: Open University Press.

3. Black, P. \& William, D. (1998). Assessment and Classroom Learning, Assessment in Education, 5(1), pp.7-74.

4. Mirvis, P., Neilsen, E. \& Pasmore, W. (2013). In P. Reason \&H. Bradbury (Eds.), Handbook of Action Research, $2^{\text {nd }}$ edn., London: SAGE Publications, pp. 77-92.

5. Cole, M. (1990). Cognitive Development and Formal Schooling; the Evidence from Cross-Cultural Research, In L. Moll (Ed.) Vygotsky and Education; Instructional Implications and Applications of Socio Historical Psychology, Cambridge: Cambridge University Press.

6. Craig, D.V. (2009). Action Research Essentials, San Francisco: John Wiley Sons.

7. Creswell, J.W (2013). Qualitative Inquiry Research Design, $3^{\text {rd }}$ ed. California: Sage Publications.

8. Gibbs, G. \& Simpson, C. (2002). Does Your Assignment Support Your Students' Learning? Retrieved www.brookes.ac.uk/services/ocsd/lunchtime_gibbs.html

9. Greenwood, D. \& Levin, M. (2000). Reconstructing the relationships between universities and society through action research, in Norman Denzin and Yvonna Lincoln (eds), Handbook of Qualitative Research, 2nd ed., Thousand Oaks, CA: Sage, 85-106.

10. Guba, E.G. \& Lincoln, Y.S. (1994). Competing Paradigms in Qualitative Research, in N.Denzin, and Y.S Lincoln (eds), Handbook of Qualitative Research. Thousand Oaks, CA: SAGE Publications. pp.105-117.

11. Gustavsen, B. (2001). Theory and Practice: The Mediating Discourse. In P. Reason \& H. Bradbury (Eds.), Handbook of Action Research, London: SAGE, pp. 17-26.

12. Gustavsen, B. (2008). Action Research, Practical Challenges and The Formation of Theory, Sage Publications, 6(4), pp.421-437.

13. Hattie, J.A. (1985). Identifying the Salient Facets of a Model of Student Learning: A Synthesis of Meta-Analyses, International Journal of Educational Research, 11, pp.187-212.

14. Howell, K.E. \& Annansingh, F. (2013). Knowledge generation and sharing in UK universities: A tale of two cultures? International Journal of Information Management, 33(1), pp. 32-39. 
15. Kant, I. (1995). On the common saying: this may be true in theory but it does not apply in practice, in H. Reiss (ed.), Political Writings. Cambridge: Cambridge University Press.

16. Lewin, K., LIippit, R. \& White, R.K. (1939). Patterns of Aggressive Behavior in Experimentally Created Social Climates, Journal of Social Psychology, 10, pp.271-301. PGCAP 600 Handbook (2014-2015), Plymouth University.

17. Rust, C., O'Donovon, B. \& Price, M. (2005). A Social Constructivist Assessment Process Model: How the Research Literature Shows Us This Could be Best Practice, Assessment \& Evaluation in Higher Education, 30, 3, pp.231-240.

18. Schwandt, T.A. (2001). Dictionary of Qualitative Inquiry, $2^{\text {nd }}$ ed. Thousand Oaks, California: Sage Publications.

19. Scribner, S. (1985). Vvgotsky's Uses of History, In J. Welrtsch (Ed.) Culture, Communication and Cognition: Vygotskian Perspectives, Cambridge: Cambridge University Press, pp.119-145.

20. Smith, M.E., Richard, T. \& Paul, J. (2012). Management Research, $4^{\text {th }}$ edn, London: Sage Publications. 